\title{
SACRIFÍCIO DAS FORMAS: DA ESTÉTICA AO SUJEITO
}

\author{
Washington L. L. Drummond ${ }^{1}$
}

RESUMO: As formas trocam-se, emergem, desaparecem. Da estética ao sujeito esse jogo interminável, pela sua tragicidade alegre, assume o sacrifício quanto a sua intensidade. Os estilos se dissolvem, o sujeito é deposto. O informe é essa ameaça constante ao que se quer estético, enquanto o inumano é a "noite terrível" do sujeito. Este trabalho analisa essas tensões através da escrita ensaística e novelista de Georges Bataille.

PALAVRAS-CHAVE: Inumano; Sujeito; Bataille.

ABSTRACT: The forms change themselves, emerge and disappear. From the aesthetics to the subject, this endless game, for its joyful tragedy, shoulders the sacrifice for its intensity. The styles are dissolved and the subject is deposed. The formless constantly threats what it is aesthetic, while the inhumanity is the subject's "terrible night". This work analyses these tensions throughout Georges Bataille's essay writings and novels.

KEYWORDS: Inhumanity; Subject; Bataille. 

"l'exubérancecorruptrice de lavie"

Cioran

\section{PARTE I: 0 JOGO DAS FORMAS}

\section{1.}

O escritor e arquivista francês Georges Bataille, nas primeiras décadas do século XX, desenvolveu uma poderosa crítica aos processos de homogeneização vigentes na época das vanguardas modernas e do fascismo alemão. Seus escritos concorreram para o norteamento das pesquisas de Michel Foucault, o qual, em diversos momentos, declarou a sua filiação a um projeto que postulava a soberania, a dissolução do sujeito ocidental e as impossibilidades das práticas da escrita e da experiência. Entretanto, as relações entre as pesquisas heteorológicas de Bataille dos anos 30 e o trabalho historiográfico foucaultiano ainda são pouco estudadas. Ao buscar os arquivos das instituições que confinam doentes, loucos e delinquentes, dando visibilidade às pequenas batalhas entre os indivíduos e os espaços institucionais, os estudos foucaultianos parecem querer transformar em discurso histórico as visadas sociológicas e políticas dos escritos bataillianos críticos do produtivismo da sociedade capitalista. Para Bataille (1987), as sociedades que se especializaram na produção e consumo de mercadorias, sob a égide de um estado forte, convergiram para a segurança dos comportamentos enquadrados em formas constantes, repetitivas e ordenadas, derivadas da equivalência de todas as mercadorias sob o signo do capital que, no seu bojo, rejeitava tudo que o ameaçasse.

O conhecimento desenvolvido em uma aplicação direta na rede produtiva, as regras do convívio burguês e seu 


\section{SACRIFÍCIO DAS FORMAS: DA ESTÉTICA AO SUJEITO}

imperialismo sobre as rotinas cotidianas e marcadamente utilitárias, tentavam solapar aquilo que a poesia e a estética romântica preconizaram como antídoto: a embriaguez $\mathrm{e}$ as formas extáticas. Rimbaud, com o desregramento dos sentidos, reaparece como apreensão sociológica do sonho e do estranho, perseguidos pelo movimento surrealista. No obscuro mundo heterológico, o sonho transforma-se em pesadelo e o estranho assume sua face perversa como o horror absoluto, disseminado em práticas dispersas na banalidade do cotidiano. $\mathrm{O}$ conjunto desses fenômenos, impuros e heterogêneos, produzia, por sua vez, no confronto com as forças homogeneizadoras da vida $\mathrm{e}$ dos indivíduos, formas singulares, informes e heterológicas.

O termo heterologia, oriundo da anatomopatologia, está inicialmente ligado à morbidez dos tecidos, sendoredefinido por Bataille como uma espécie de economia dos resíduos, de restos não assimiláveis, por vezes abjetos, que rompem e esgarçam as estruturas homogêneas, afirmando aquilo que não pode ser recuperável e que corrompe as formas. A excreção excessiva desses procedimentos colabora para a decomposição dos corpos, instaurando a heterogeneidade no seio do que se quer homogêneo, forçando o aparecimento de singularidades que, longe de afirmar algo preciso, colocam-se em jogo, sem reservas, numa lógica do desperdício e do excesso. Deslocando-se pelo esgotamento das formas assimiladas, as heterogeneidades movem-se no gasto sem recuperação, no espaço mesmo do consumo e utilitarismo burguês, em que indivíduos são medidos pela funcionalidade no sistema produtivo e encontram a realização no acúmulo de bens e nas práticas permitidas socialmente, desde a fruição estética até o gozo erótico. Decompondo esse espaço, criando 
fissuras, corrompendo antigos conluios, estabelece uma zona informe em que tudo o que é constituído está ameaçado. Aos imperativos dos indivíduos burgueses, a preservação e o cuidado de si, contrapõe-se a extenuação completa, excessiva, através, sobretudo, da transgressão sacrificial do erotismo e da estética. A própria heterologia seria uma paródia da ciência burguesaeinstrumental. Doinformeedodispêndiosem finalidade, tanto na arte quanto no descuidar de si, brotam os personagens que constituem a escória da sociedade burguesa e povoam os curtos romances de Bataille: loucos, prostitutas, escroques, uma gama de celerados os quais concorrem, aliados da estética vanguardista, para a corrosão das formas em sua contingência histórica. A heterologia vai se opor a qualquer possibilidade de representação homogênea da realidade, daí o conceito de informe.

O informebatailliano tem gerado mal-entendidos, pois vem sendo aplicado como medida de avaliação estéticaou mesmo como uma nova estética,imaginado como materialização sem forma e ainda como a substancialização de trocas duais e perenes. Entretanto, não é um conceito fundante pelo qual se possa erigir uma estética ou política, mas justo o contrário: atua como a dissolução sacrificial do constituído, do edificado, daquilo que se dá enquanto sistema. Se alijado desse caráter desagregador, corruptivo, torna-se um movimento estético, um estilo, purificado por sua parte maldita. Parte desses equívocos pode ser creditado no desprezo às emergências históricas e no próprio efeito de homogeneidade social que traga a própria teoria, a estética e o pensamento crítico. Em contrapartida, concebemos o informe indiscernível dos processos heterológicos para que assim as singularidades não sejam capturadas pelo pensamento e arrastadas, impotentes, para o espaço inóspito do homogêneo e do já acontecido. 
Para Bataille, o informe, pensado num contexto heterológico, emerge como um operador, não para imaginar o sem forma, mas para denunciar e desqualificar as formas vigentes em sua implicação com o que se espera no domínio social, político e estético. Insta o aparecimento do insólito para que o estranho não seja capturado pelo pensamento, arrastado, impotente, para o homogêneo e expurgado de sua parte maldita. O sentimento de pavor e recusa daquilo que assusta, por nunca antes ter sido experimentado ou pensado, seria provocado pelo informe que ameaça a ordem vigente, ao mundo harmonioso aliado às exigências produtivas (sejam econômicas ou sexuais). Esse efeito desagregador é similarao ruído no universo musical, força do caos que ronda a consonância harmônica e toda regularização sonora que reflete a ordem das coisas. O ruído é essa fissura, fenda barulhenta da/na organização da escala sonora (e cromática!) que ultrapassa a ambiência musical, pois, como o informe, ameaça a própria ordem simbólica que dá sentido ao mundo.

O informe, dessa maneira, não pode ser medida de nada, pois em seus procedimentos sacrificiais, joga com as formas singulares, excrescências derrisórias do mesmo. Heterologia e informe são constitutivas de heterotopias - espaços sem mapas ou cartografias - e alteridades.

\title{
PARTE II: DEPOSIÇÃO DO SUJEITO: EROTISMO E NARRAÇÃO
}

\author{
1. \\ "a beleza será convulsiva ou não será" \\ Breton
}


Embora o livro de Georges Bataille seja celebrado pelo seu teor erótico, a novela História do Olho deveria ser tomada como um pequeno breviário sobre a constituição do sujeito moderno. Num intricado miseenabîme, deslocamentos e intervenções concorrem para mascarar aquele que escreve, produzindo lugares de fala labirínticos. Estes procedimentos podem ser resumidos em sua famosa frase: "escrevo para esquecer meu nome" (BATAILLE, 2004, 612). O que, a primeira vista, poderia ser apenas um jogo literário - tendo o autor como protagonista - estende-se por toda a sua multifacetada obra com uma postulação precisa: o sujeito transita, por processos sacrificiais, entre o longo e penoso processo de individuação até ao seu apagamento provocado em situações limites. $\mathrm{O}$ autor e sua via crucis tragicômica numa miríade de relatos pseudo-biográficos, narrações não identificadas, prólogos e epílogos, nomes próprios e pseudônimos, não passa de avatar do sujeito em dissolução - uma persona que tematiza a formação e a deformação do sujeito empreendida na obra batailliana. Não será coincidência a apropriação do tema autoral no escandaloso, e vencido, debate estruturalista dos anos 60 promovido por Foucault (O que é um autor?), Barthes (A morte do autor) e replicado contemporaneamente por Agamben $(O$ autor como gesto), embora a forma fria, estrutural, racionalizada, expurgada do erotismo, seja estranha ao nosso convulsivo autor, pois na escrita batailliana os contornos trágico-poéticos atingem uma dimensão sacrificial e cosmológica. Pode-se dizer que nos textos estruturalistas, Bataille e Blanchot estão expostos como a vianda de Velasquez está exposta nos quadros de Francis Bacon. Um pouco diferente a epígrafe incisiva (e sisuda apesar do riso batailliano!) escrita por Foucault (1973, p.28) na abertura de sua Arqueologia do Saber : "Não, eu não estou lá onde me querem espreitar, mas aqui de onde os observo rindo (...) Mais de um, como eu sem dúvida, escreveram para não mais ter um rosto". ${ }^{2} \mathrm{~A}$ 
narração não remete a um antes (aí a psicanálise nada pode com seu impulso de negação do presente e remissão do passado), nem a um em si, apenas difração, disrupção, encenação sacrificial...

2.

Em Bataille, o erotismo está como um meio, uma experiência dos limites, por isso impossível, em que a identidade do sujeito é reduzida a uma máscara que tem como segredo nada encobrir além da dissolução: a individuação é colocada a nu ameaçada por uma negatividade de intensidade igual. A economia erótica concorre para a dissipação, para o gasto sacrificial contra o acúmulo. Assim, o erotismo explícito dessa terrível novela decepciona aos amantes do gênero, não é ao prazer que os desesperados personagens visam, mas à nadificação do eu, numa liturgia precisa, tortuosa e nada edificante. Lembremos dos temas românticos arrematados por Rimbaudao apelar para um sistemático desregramento de todos os sentidos e sobretudo dos escritos do Marques de Sade que escreve obras pedagógicas, sátiras dos livros destinados à formação, em que descreve os atos mais terríveis que intentam ultrapassar - em Bataille seria "transgredir" - os limites da moral e do humano. Entretanto, se a transgressão ainda é possível ela é temporal e reversível, remetendo o indivíduo que a persegue a uma escalada sem fim e que invariavelmente o levará a explorar os limites impostos pelos processos homogeneizantes (políticos e estéticos) que possibilitam a vida social enquanto ordem burguesa, pecuniária, reprodutiva.

A repetição da lição sadeana em Bataille indica que a escalada sacrificial em direção a todos os excessos leva ao ilimitado, a um misticismo sem deus, rumo ao inumano. É porque as formas humanas aqui são instáveis e longe de suas mediações morais e estéticas se projetam enquanto informes - dramatizado pelo 
olho, às vezes ovo, deslocando-se sempre de cavidades em que nada lhe é próprio sob o assombro da morte (morte da previsível armação estética fiduciária, morte do corpo como imagem fechada e vertical, morte do indivíduo consciente e autonomizado). A relação entre a obscenidade e o escatológico é apresentada sob a (de) formação corporal, friccionando a estetização artística do corpo e sua gramática visual. A visão, mas que o olho, é a personagem principal da novela, está no lugar dos intrincados desenhos sociais que estabelecem seus regimes de visibilidade tanto na arte como na vida social. A presença da mãe impassível a observar o que não deveria ser visto - os perversos desdobramentos eróticos dos adolescentes, não inibe, antes faz esse jogo duplo do interdito que garante o gozo na tentativa de ultrapassálo (transgredir), sinal trocado que as proibições espargem no social. Nunca reprimem, incitam ao ato perverso. Pois o gozo, como o "si" nunca está simplesmente no "interior" do individuo, mas percorre uma longa serie de trajetórias entre o social e o privado, entre a superfície e sua dobra - na exterioridade da ordem simbólica. O olho cortado em Dali/ Buñuel, (citação da novela de Bataille?) não visa apenas às imagens cinematográficas, é a ruptura radical da visão, de seu regime burguês, abrindo a possibilidade do visto para além do institucionalizado. É um excesso.

\section{3.}

Excesso e êxtase se aproximam nessa mística sem deus e chafurdam na matéria corporal, eis seu altar, por vezes ampliado pela lama (num devir animal, margeando o inumano) em conluio com a chuva, os raios, o cosmo - olho e ânus solar (no eu moderno-romântico suprime-se a distinção entre a paisagem 
interior e exterior, desde Werther elas se confundem, convulsas). O prazer erótico não advém do gozo sexual mas da transgressão do interdito, dos limites impostos pela ordem simbólica a qual investe na própria atividade sexual,no imperativo reprodutivo e no êxtase submetido a uma gramática. Os personagens da História do Olho evitam a forma canônica e desviam, deslocam, o gesto até que se cansam dos jogos quase infantis, quando lúbricos e desesperados lançam-se nos jogos de morte - o assassínio como última ultrapassagem. Bataille escreveu que "o sentido último do erotismo é a morte". Interpreto a boutade de Lacan de que "não existe relação sexual", considerando a formulação batailliana: como poderia haver alguma relação no momento mesmo em que o gozo, a "petite morte" (como a língua francesa nomeia o êxtase sexual) dissolve o sujeito, revertendo por instantes o processo de individuação? O erotismo encena parodicamente a continuidade e descontinuidade do indivíduo destinado à morte, indo deste à espécie e desta revindo ao indivíduo. Bataille (2004, p.19) escreve em seu ensaio sobre o erotismo que "para nós que somos seres descontínuos, a morte tem o sentido da continuidade do ser: a reprodução leva à descontinuidade dos seres, mas põe em jogo sua continuidade".

\section{4.}

Passamos do pseudônimo, ainda lance pueril do autor, à máscara - na deposição/desapropriação do sujeito - e daí ao inumano, visada radical da alteridade. Em cada uma das inflexões a "obscura encenação do caos" - pois nada de nosso encobrem - ressoa a frase de Hegel: "o ser humano é essa noite, esse nada vazio, que contém tudo - uma riqueza infinita de muitas representações, imagens, das quais nenhuma pertence a 
ele". Bataille reteve para nós o vazio que essa "noite terrível" tenta encobrir, agora, ainda mais terrível pois, em sua dialética irresoluta, nos confina na reversão sem cessar das formas. Seria então esse o efeito que faz "de cada forma noturna um espelho ameaçador do enigma insolúvel que o ser mortal vislumbra diante de si"?

\section{NOTAS}

${ }^{1}$ Professor Permanente do Programa de Pós-graduação em Crítica Cultural (Uneb) e Colaborador no Programade Arquitetura e Urbanismo (Ufba). Coordenador do grupo de pesquisa Pós-Teoria.

${ }^{2}$ "Non, non je ne suis pas là où vous me guettez, mais ici d’où je vous regarde en riant (...). Plus d'un, comme moi sans doute, écrivent pour n’avoir plus de visage." 


\section{REFERÊNCIAS}

BATAILLE, G. Romans et récits. Paris: Editions Gallimard, 2004.

BATAILle, G. Histoire de L'Oeil. Oeuvres Complètes. Paris: Editions Gallimard, 1970.

BATAILLE, G. L'Érotisme. Paris: Editions Minuit, 2004.

FOUCAULT, M. L'Archèologie du Savoir. Paris: Editions Gallimard, 2008. 